\title{
ANTIGO HOTEL MUNICIPAL: PRESIDENTE PRUDENTE - SP
}

Beatriz Aparecida Silva de Lima, Fabrícia Dias da Cunha de Moraes Fernandes Borges.

Universidade do Oeste Paulista - UNOESTE, Curso de Arquitetura e Urbanismo, Presidente Prudente, São Paulo. E-mail: bia.arqeurb@gmail.com

\section{RESUMO}

Esta pesquisa mostrará um breve estudo feito do Antigo Hotel Municipal, apresentando um pouco de sua história e importância para a cidade de Presidente Prudente. O objetivo deste estudo foi apresentar sua relevância para a memória da cidade, mostrando a importância da preservação do patrimônio histórico e da perpetuação da memória de um povo, visto que, atualmente, esta edificação se encontra descaracterizada de sua obra original e estagnada no tempo. Foram feitos levantamentos bibliográficos sobre patrimônio histórico, memória e identidade, levantamento de dados sobre o local estudado e histórico do edifício na Prefeitura de Presidente Prudente, Museu Histórico, Acervo histórico da UNESP, sites, livros, artigos eletrônicos, teses, levantamentos fotográfico e métrico. O presente artigo visa mostrar que o Antigo Hotel possui grande valor histórico para a formação da história da cidade, visto sua relevância para preservação da memória local, mostrando que através desta, há outras edificações de interesse cultural local.

Palavras-chave: Antigo Hotel Municipal, Presidente Prudente, Patrimônio Histórico, Preservação, Memória.

\section{OLD TOWN HOTEL: PRESIDENTE PRUDENTE - SP}

\begin{abstract}
This research will show a brief study of the Old City Hotel, with a bit of its history and importance to the city of Presidente Prudente. The aim of this study was to present its relevance to the memory of the city, showing the importance of cultural heritage preservation and perpetuation of the memory of a people, as currently this building is uncharacteristic of his original and stagnant work in time. literature surveys were made about historical heritage, memory and identity, data collection on the study and historical site of the building in Presidente Prudente Hall, Historical Museum, Historical Collection of the UNESP, websites, books, electronic items, theses, photographic surveys and metric. This article aims to show that the Old Hotel has great historical value for the formation of the history of the city, as its relevance to the preservation of local memory, showing that through this, there are other buildings of local cultural interest.

Keywords: Old Town Hotel, Presidente Prudente, Heritage, Preservation, Memory.
\end{abstract}




\section{INTRODUÇÃO}

Com o descaso dos prédios históricos de Presidente Prudente, há a preocupação do que se fazer com tais edifícios para a preservação da história e memória da cidade escrita através dessas obras. O que fazer para preservar o prédio histórico como garantia de perpetuação de memória da cidade? Somente o tombamento não traz a salvaguarda desses edifícios, mas, este objeto de preservação unido a novos usos para tais prédios históricos pode gerar a salvaguarda e preservação desses edifícios ao invés de demoli-los, deste modo, teremos a valorização do espaço, do edifício, a preservação do patrimônio entre outros aspectos positivos.

Deste modo, o objetivo deste trabalho foi estudar sobre a importância histórica que essa edificação tem, mostrando o que o Antigo Hotel Municipal foi e como se encontra atualmente e revelando o valor que ele possui para a formação e perpetuação da memória da cidade de Presidente Prudente e da sociedade.

\section{METODOLOGIA}

Para estudo deste trabalho foi realizado levantamento bibliográfico e documental para a coleta de informações sobre a edificação em estudo para a mostra da veracidade dos dados através das respectivas fontes de pesquisa: Prefeitura Municipal de Presidente Prudente; Museu Histórico; Acervo histórico da UNESP; sites, livros, artigos, teses entre outros relacionados ao tema, além dos levantamentos métrico e fotográfico.

\section{RESULTADOS}

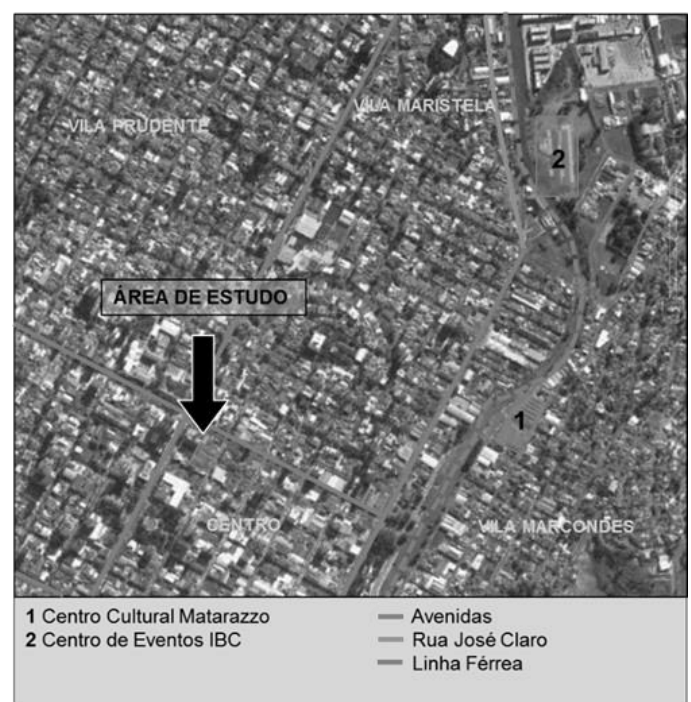

Figura 01. Localização do Antigo Hotel Municipal no quadrilátero central. Fonte: Google Maps (2016). Editado pela autora (2016).

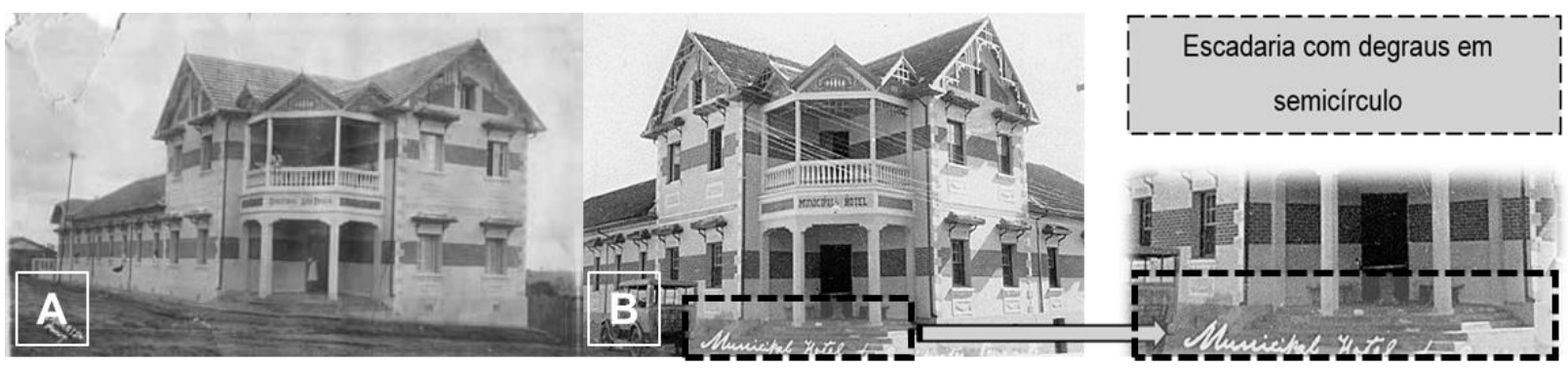

Figura 02. A) Sanatório São Paulo, 1930; B) Fachada do Antigo Hotel Municipal.

Fonte: Museu e Arquivo Histórico Municipal Prefeito Antonio Sandoval Neto (1950 e 2016). Montagem elaborada pela autora (2016). 

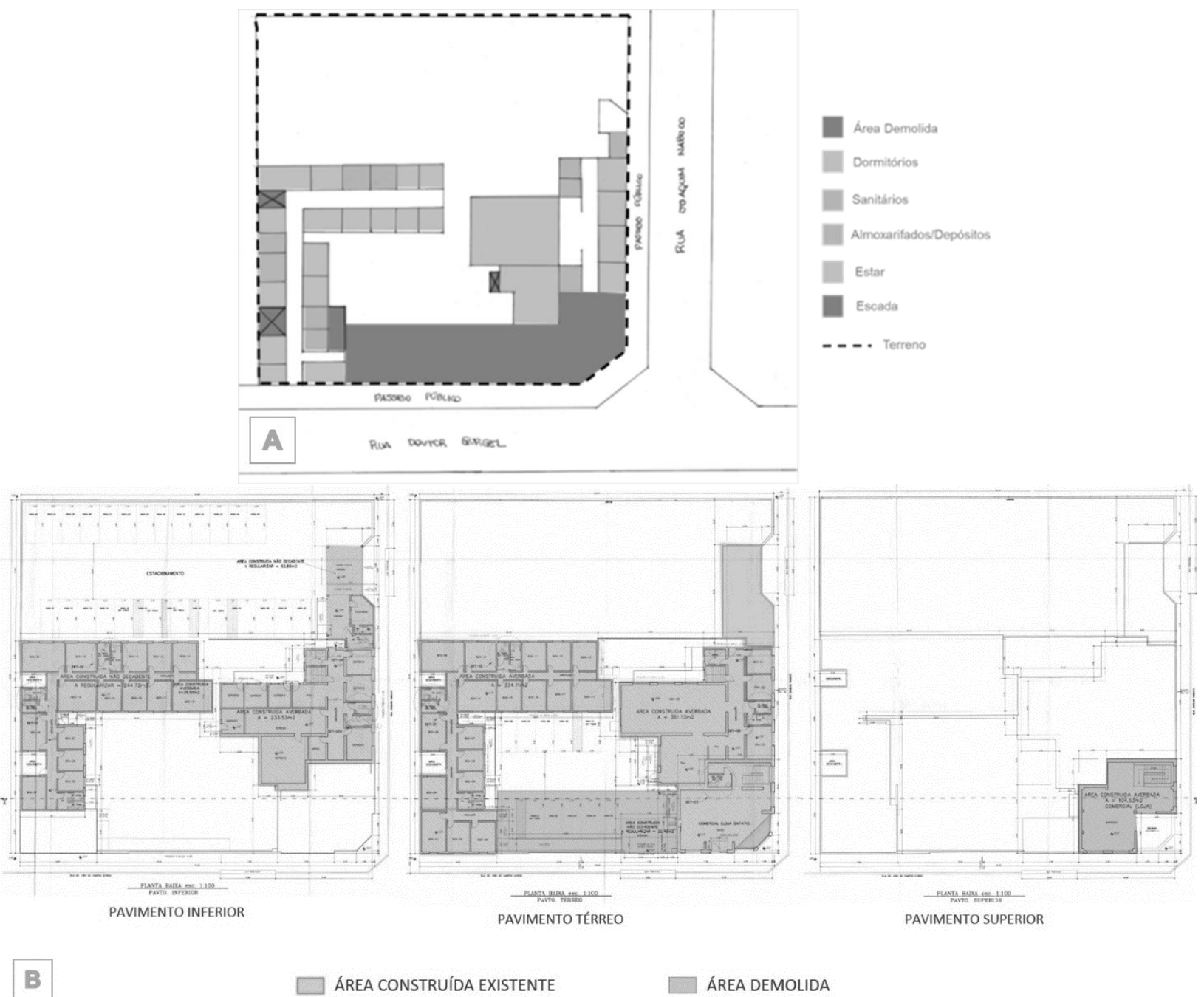

$\square$ ÁREA CONSTRUÍDA EXISTENTE

$\square$ ÁREA DEMOLIDA

Figura 03. A) Planta baixa do Antigo Hotel Municipal em situação atual; B) Planta pavimento inferior, térreo e superior do projeto aprovado.

Fonte: Prefeitura Municipal de Presidente Prudente (2016). Editado pela autora, sem escala (2016).

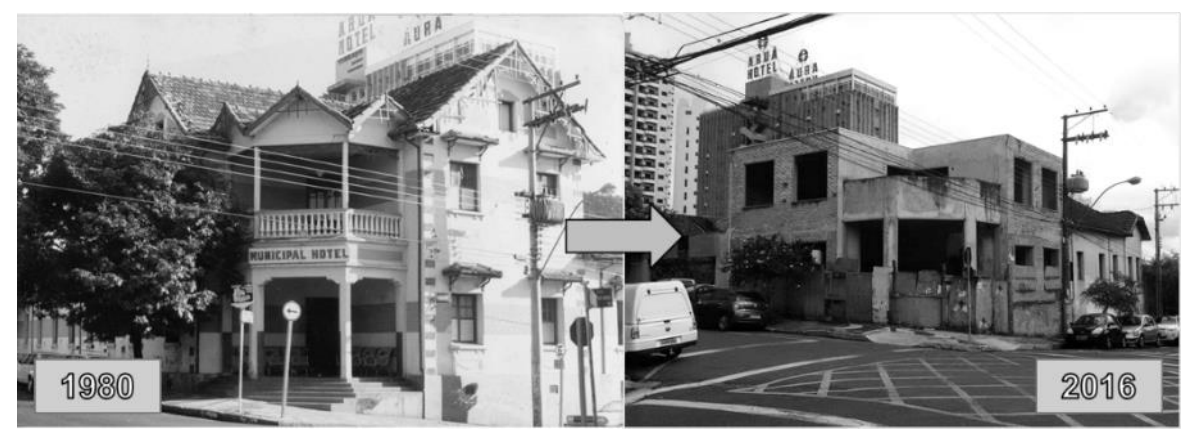

Figura 04. Antes e depois: fachada principal do Antigo Hotel Municipal em 1980 e 2016.

Fonte: Acervo Museu e Arquivo Histórico Municipal Prefeito Antonio Sandoval Neto (1980) e acervo pessoal (2016). Montagem elaborada pela autora (2016).

\section{DISCUSSÃO}

Presidente Prudente foi fundada em 1917, pelo Coronel Francisco de Paula Goulart, onde ela nasceu através da expansão cafeeira que vinha pelo extremo oeste de São Paulo, que se deu com o desenvolvimento da Estrada de Ferro Sorocabana em questão do Rio Paraná (ABREU, 1997, apud D'INCAO, 2007). Segundo dados do IBGE (2016), abrigava em 2010, em torno de 207.610 mil habitantes, onde está localizada a oeste da capital do estado, distando desta cerca de $558 \mathrm{~km}$ da mesma. 
Assim como outras cidades brasileiras, Presidente Prudente teve sua fundação e início do processo de urbanização no início do século $X X$, onde, seu patrimônio histórico, principalmente o edificado, encontra-se em descaso. Não possuímos grandiosas obras, porém, as que existem são destacadas pelos materiais que haviam em mãos disponível no local na época, e que fazem parte de um processo urbanístico (HIRAO; FLOETER, 2012).

As edificações, mesmo que seus valores estéticos não sejam tão claros, são destacadas pelos métodos construtivos e pela mão de obra que havia no momento em que foram construídas, assim como o Antigo Hotel Municipal de Presidente Prudente, e, por isso, iremos mostrar sua importância para a memória e formação da história da cidade.

O Antigo Hotel Municipal, inicialmente, antes de ser concebido com tal objetivo, havia sido construído para ser usado com a Segunda Casa de Saúde da cidade. O projeto situava-se na Rua Nilo Peçanha, número 715, que, após um certo tempo, seu projeto fora modificado para ser utilizado como o Antigo Hotel Municipal, que se encontra hoje localizado dentro do quadrilátero central da cidade, estabelecido na rua Joaquim Nabuco, número 470, esquina com a rua Doutor Gurgel (RESENDE, 2006).

Segundo Resende (2006), o projeto original - o hospital - continha duas alas de quartos individuais, uma cozinha grande e dois salões anexos, com uma área total de construção de 1940 $\mathrm{m}^{2}$. Detalhes como de azulejos lusitanos abaixo das janelas lembravam os edifícios portugueses de antigamente, onde em cima das mesmas, haviam pequenas abas com coberturas de telhas.

Ainda segundo o autor, sua entrada principal se dava pela esquina, onde continha uma escadaria com seis degraus semicírculos. Nessa área, haviam cadeiras de madeira com armação de ferro, que serviam para repouso aos hospedes para descanso após o almoço, que atualmente, se encontram no Museu e Arquivo Histórico Municipal.

Dr. Romeu Leão Cavalcanti, o construtor do hospital, vendeu o edifício pouco tempo depois de construído para o Monsenhor Sarrion, que o converteu em um sanatório e onde levou duas freiras da Irmandade de São Vicente de Paulo para tomarem conta do hospital e o administrar, com o objetivo de, por meio da Conferência Vicentina, ajudar o povo necessitado de Prudente e região. Porém, um ano e meio depois, não foi possível pagar a dívida, e por esse motivo, Monsenhor Sarrion teve de devolvê-lo ao proprietário inicial, Dr. Cavalcanti (RESENDE, 2006).

O autor cita que o projeto se passou então de Sanatório para Hotel Municipal, que obteve esse nome por meio de uma família de alemães, onde, um casal português, José Maria Gonçalves e Leonilda Kark Gonçalves adquiriram o mesmo. O hotel nasce então em 1943. Desde então, ficou conhecido na região como "o melhor hotel de Prudente" (RESENDE, 2006, p. 85).

Sua popularidade se deu por conta dos próprios viajantes, onde estes espalhavam a notícia por todas as cidades do Estado, fazendo com que a atenção fosse chamada para o hotel, atraindo juízes, professores secundários, gerentes de empresas algodoeiras, promotores, e ali ficavam enquanto obtivessem resultado em sua carreira na cidade.

O mesmo passou por uma época em que estava prestes a desabar, onde foi manchete até de jornal. A obra também passou por um momento onde foi parcialmente destruída, no final da década de 1990, logo após o CONDEPHAAT (Conselho de Defesa do Patrimônio Histórico, Arqueológico, Artístico e Turístico do Município), ter discutido a possibilidade de tombamento da obra.

Segundo Bernardi e Hirao (2011), antes que esse processo fosse iniciado, parte principal da obra fora descaracterizada, juntamente com a tão bela escadaria com degraus em semicírculo, destruindo totalmente sua fachada para que não houvesse a sua inscrição no livro do tombo, onde o mesmo, logo após declararem a intenção de conservá-lo e registrá-lo como um Bem Patrimonial, foi parcialmente destruído na mesma madrugada.

Atualmente, apenas três bens patrimoniais são tombados, sendo eles o Bebedouro de Animais localizado em frente a Antiga Estação Ferroviária e atual Procon (decreto n. 5.513 de 12 
de abril de 1985), o Centro Cultural Matarazzo, conhecido como Antigo Barracões da IRF Matarazzo (Indústrias Reunidas Fábricas Matarazzo) (decreto n. 6.128 de 30 de abril de 1987) e o Museu e Arquivo Histórico, conhecido também como o Antigo Matadouro da cidade (decreto n.으 7.643 de 03 de Julho de 1991) (HIRAO, FLOETER, 2012).

Ainda hoje, sobram vestígios do tempo, poucos, mas que ainda sim, lembram de como o Antigo Hotel Municipal era. Os telhados, algumas janelas e paredes externas ainda estão no mesmo lugar e da mesma maneira em que deveriam estar a obra por inteiro. Porém, o que vemos hoje, não há relação alguma com o seu passado, danificando assim, "o caráter e integridade da edificação e do centro histórico de Presidente Prudente" (BERNARDI; HIRAO, 2011).

Atualmente, o prédio se encontra desativado e apenas com o estacionamento em uso. Os proprietários já foram acionados diversas vezes para a reforma da obra, pois ela se encontra em ruínas, e sua localização na área central traz preocupação para os moradores e para a população em geral, especificamente para o poder público municipal.

Ainda segundo os autores, a prefeitura é acionada diversas vezes pelo uso indevido do local por usuários de drogas e moradores de rua, o que traz preocupação para os moradores do entorno. Deste modo, o poder público pede-se que se deve adotar alguma medida para que o mesmo tenha uma utilidade para a sociedade e assim haver a reabilitação do prédio.

Em 2010, o proprietário iniciou uma reforma do que restou da obra que buscaria o traçado original do edifício. Na fachada onde o estacionamento está ativo, que se encontra na Rua Dr. Gurgel:

O projeto contava com a reconstrução do antigo bloco na mesma proporção, porém, no lugar de dormitórios, seriam instalados sete lojas de vestuário, com acesso direto à rua e sem circulação central. Na esquina, que antes abrigava a recepção do hotel, seria instalado um café. Já no segundo pavimento os serviços e administração (BERNARDI; HIRAO, 2011).

O proprietário entrou em desacordo com os profissionais e por esse fato, a obra foi embargada em outubro do mesmo ano. Segundo o secretário municipal de Planejamento, Desenvolvimento Urbano e Habitação (Seplan), Laércio Batista de Alcântara, "a paralisação foi necessária, pois a obra não possui aprovação do projeto para início das atividades". Porém, após esse desentendimento, a obra continua da mesma maneira até os dias de hoje, sem nenhuma alteração a mais, porém, já desembargada.

Conforme dados obtidos pela Prefeitura Municipal de Presidente Prudente, podemos encontrar um projeto comercial que está aprovado desde 2012, porém, que ainda não foi executado por falta de verba do proprietário. Na planta, vemos três níveis, constituídos por pavimento inferior, pavimento térreo e primeiro pavimento. O projeto mantém toda a estrutura da preexistência, onde no pavimento inferior podemos encontrar alguns boxes, depósitos, adega, estoque, circulações, sanitários, áreas descobertas que acompanham até o último pavimento, escritório, varanda e um estacionamento. No pavimento térreo possuem mais boxes, sanitários, halls, circulações, salão, uma área menor de estacionamento e um jardim. Já no pavimento superior, encontram-se apenas um depósito e uma sacada. Ainda nessas plantas, algumas áreas construídas são averbadas e outras não decadentes a regularizar. Na Figura 3-A, vemos a planta baixa do Hotel com os ambientes existentes do Hotel e a área demolida e na Figura 3-B, vemos as plantas do projeto aprovado com as áreas existentes e demolidas.

Com essas intervenções projetuais feitas no prédio, houve então a descaracterização do imóvel, fazendo com que acontecesse o desinteresse de preservação pela obra como Patrimônio Histórico e Arquitetônico. No local, encontramos assim, parte do passado se contrapondo com o presente, descaracterizado e abandonado, em ruínas. 


\section{CONCLUSÃO}

O Antigo Hotel Municipal preserva muitas histórias, lembranças que quem passava por ali, deixava. Desde altos negócios, apostas, ou até romances. Um lugar onde reserva muitas vivências que o tempo não pode apagar, onde as histórias ficarão gravadas para sempre na memória individual, e que, através da preservação, é possível que fiquem gravadas na memória coletiva desse povo. Seus vestígios do que foi são poucos, mas existentes. Para a preservação e permanência da memória dessa obra, é necessário que se verifique formas de intervenção para a salvaguarda desse edifício e de tantas histórias e lembranças que ali há. Seu estado atual não impede que sejam feitas novas propostas de usos para tal localidade, mas, sim, propõe um desafio de preservar aquilo que ainda há de se perpetuar por várias gerações, criando não apenas uma nova edificação ou dando a ele um novo uso, mas, que ainda assim, mostre seu real valor para a sociedade.

\section{REFERÊNCIAS}

BERNARDI, G. G.; HIRAO, H. O antigo hotel municipal de presidente prudente demolição do edifício e descaracterização da paisagem do centro histórico, v. 5, n. 2, 2011. Disponível em: http://revista.fct.unesp.br/index.php/topos/article/view/2288>. Acesso em: 18 fev. 2016.

D'INCÃO, M. A. (Org.). Presidente Prudente - Capital Regional. Presidente Prudente, São Paulo: Letras À Margem, 2007.

HIRAO, H; FLOETER, R. A. O patrimônio arquitetônico e urbanístico de Presidente Prudente: o possível preservado. Revista Tópos, V. 6, N², p. 53 - 68, 2012. Acesso em: 18 fev. 2016.

IBGE. Instituto Brasileiro de Geografia e Estatística. Disponível em: <http://cidades.ibge.gov.br/xtras/perfil.php?lang=\&codmun=354140\&search=| | infogr\%E1ficos:informa\%E7\%F5es-completas>. Acesso em: 23 mai. 2016.

RESENDE, B. Raízes Prudentinas 2. 1. ed. Presidente Prudente: Editora do autor, 2006. 